\title{
A POSSIBLE ASSOCIATION BETWEEN GINGIVAL CREVICULAR FLUID INFLAMMATORY CYTOKINES AND RHEUMATOID ARTHRITIS DISEASE ACTIVITY
}

\author{
Maha Mahmoud"; Rania AbdElAziz Fahmy ${ }^{* *}$ and Mona mohamed Ashraf ${ }^{* * *}$
}

\begin{abstract}
Backgroud: Rheumatoid arthritis (RA) and chronic periodontitis are the most common chronic inflammatory diseases with remarkable pathological and clinical similarities

Aim: This study was performed to determine a possible relation between the severity of chronic periodontitis together with increased local inflammation of the periodontium and RA disease activity.

Methods: This study was conducted on 20 patients with Rheumatoid Arthritis fulfilling the 2010 ACR/EULAR classification criteria for RA. All subjects were recruited from those attending the Rheumatology Unit and Rheumatology outpatient clinic at the Alexandria main University Hospital. Rheumatoid disease activity was assessed by DAS-28 score system. The periodontal status was assessed by measuring PD, CAL, PI and GI. Local proinflammatory cytokines from the gingival crevicular fluid (GCF) were quantified including Il-6 and TNF- $\alpha$. Correlations between different parameters were assessed using Spearman coefficient
\end{abstract}

Results: A positive correlation was found between DAS2 8 and both GCF IL- 6 and TNF- $\alpha$ $(\mathrm{p}=0.694-\mathrm{r}=0.001)$ and $(\mathrm{p}=0.604-\mathrm{r}=0.005)$ for IL- 6 and TNF- $\alpha$ respectively and the values were statistically significant. A positive correlation was also found between DAS28 and each of PD $(\mathrm{p}=0.246, \mathrm{r}=0.297), \mathrm{CAL}(\mathrm{p}=0.244, \mathrm{r}=0.300), \mathrm{PI}(\mathrm{p}=0.406, \mathrm{r}=0.076)$ and $\mathrm{GI}(\mathrm{p}=0.340, \mathrm{r}=0.142)$ however the correlation was not statistically significant.

Conclusion: The findings provide evidence of a possible relation between Rheumatoid Arthritis and chronic periodontitis through sharing the same inflammatory mechanism.

\section{INTRODUCTION}

Periodontitis is defined as an inflammatory disease of the supporting tissues of the teeth caused by specific microorganisms or groups of specific microorganisms, resulting in progressive destruction of the periodontal ligament and alveolar bone with increased probing depth formation, recession, or both. ${ }^{(1)}$

* Assistant Professor of Oral Medicine, Periodontology, Oral Diagnosis and Radiology, Faculty of Dentistry, Alexandria University

** Lecturer of Oral Medicine, Peiodontology, Oral Diagnosis and Radiology, Faculty of Dentistry,Alexandria University *** Internal Medicine Specialist, Rheumatology Department, Faculty of Medicine, Alexandria University 
Apart from the local destruction of the periodontal tissues, the infected and necrotic epithelium of the ulcerated pocket lining occupy a large surface area. Surface area in generalized severe chronic and aggressive periodontitis can reach up to $20 \mathrm{~cm}^{2}$. This area of the ulcerated pocket epithelium allows exchange between bacterial and host products. ${ }^{(2-4)}$

These host-bacterial interactions produce a resultant impact on various systems in the human body ${ }^{(5)}$. Several mechanisms may participate in this interaction including those induced by oral organisms, and those associated with host response factors (such as interleukin IL-1, interleukin IL-6 and tumor necrosis factor TNF- $\alpha{ }^{(6)}$. This periodontalsystemic disease interrelationship is believed to be mediated through systemic inflammatory reactants such as acute-phase proteins and immune effectors ${ }^{(5,6)}$. Although the potential impact of many systemic disorders on the periodontium is well documented, recent evidence suggests that periodontal infection may significantly enhance the risk for various systemic diseases including rheumatoid arthritis (RA).

Rheumatoid arthritis (RA) is a chronic destructive inflammatory disease characterized by the accumulation and persistence of an inflammatory infiltrate in the synovial membrane that leads to synovitis and the destruction of the joint architecture ${ }^{(7)}$.

Although the etiologies of these two chronic inflammatory diseases are separate, the underlying pathological processes are of sufficient similarity to warrant consideration of a possible association between the two diseases. Whether RA is associated with the progression of existing inflammatory conditions, such as periodontitis, is controversial ${ }^{8-}$ ${ }^{10)}$. Hence, This study was performed to determine a possible association between the severity of chronic periodontitis and increased local inflammation of the periodontium with RA disease activity.

\section{Pateints and methods}

This study was conducted on 20 patients with Rheumatoid Arthritis fulfilling the 2010 ACR/ EULAR classification criteria for RA ${ }^{(11)}$ of less than 5 years disease duration and having chronic periodontitis according to the classification of the American Academy of Periodontology $1999^{(12)}$ with at least 20 teeth present.

All subjects were recruited from those attending the Rheumatology Unit and Rheumatology outpatient clinic at the Alexandria main University Hospital.

Exclusion criteria included smoking, diabetes mellitus, individuals who had undergone periodontal treatment including prophylaxis, and/or antibiotic therapy over the past three months, and females who were pregnant and lactating. Informed consent was provided according to the Declaration of Helsinki and obtained from all patients before the beginning of the study.

\section{Data Collection:}

Rheumatoid Arthritis assessment included RA disease activity by applying the Disease Activity Score 28 (DAS-28). The DAS system involved four parameters: 28 tender joints (TJ28), 28 swollen joints (SJC28), Erythrocyte Sedimentation Rate (ESR) and patient general health (GH) based on a $100-\mathrm{mm}$ visual analog scale. The 28 joints assessed included 10 metacarpophalangeal joint and 10 proximal interphalangeal joints of the hand, 2 wrists, 2 elbows, 2 shoulders and 2 knees. Patient GH based on a 100-mm visual analog scale was taken as: grade 0 corresponding to no disease activity and grade 100 corresponding to high disease activity. DAS score was calculated by using the formula:

\section{DAS-28 $=0.56 \sqrt{\mathrm{TJ} 28}+0.28 \sqrt{\mathrm{SJC28}}+0.70 \log$ ESR $+0.014 \mathrm{GH}$}

Rheumatoid disease activity was defined as: low, moderate and high. Low disease activity was 
confirmed if DAS-28 score was $\leq 3.2$, moderate if DAS-28 score was $3.2<$ DAS-28 score $\leq 5.1$, and high if DAS-28 score $>5.1^{(13-15)}$

Periodontal status assessment included Probing Pocket Depth(PD) ${ }^{(16)}$,Clinical Attachment Loss $(\mathrm{CAL}){ }^{(16)}$, Plaque Index (PI) ${ }^{(17)}$, Modified Gingival Index $(\mathrm{GI})^{(18)}$, and the levels of IL-6 and TNF- $\alpha$ in the gingival crevicular fluid (GCF) using ELIZA kits $^{(19,20)}$. Filter paper strips were used for GCF sampling. ${ }^{(21)}$ They were introduced into the greatest pocket depth in each patient till mild resistance was felt. They were left for 60 seconds to collect the resting $\mathrm{GCF}^{(22)}$. Strips contaminated with blood or saliva were discarded. Then the strips were put in sterile plastic eppendorf tube containing $150 \mu 1$ phosphate-buffered saline. The ependorf tubes were then centrifuged at 11.000 .

\section{Statistical analysis:}

Data of all parameters were fed to the computer and analyzed using IBM SPSS software package version 20.0. Correlations between two quantitative variables were assessed using Spearman coefficient. Significance of the obtained results was judged at the 5\% level. The association of categorical variables was assessed by chi-square test. Statistical significance was declared if the $\mathrm{P}$ value was $<0.05$.

\section{RESULTS}

The periodontal status was assessed for all 20 patients recruited for this study .The mean values were $(4.75 \pm 0.85,3.75 \pm 1.62,1.84 \pm 0.50,1.88 \pm$ 0.38 ) for PD, CAL PI and GI respectively. (Table 1)

The levels of local gingival crevicular proinflammatory cytokines were $(13.50 \pm 11.28$ and $4.34 \pm 2.61)$ for Il- 6 and TNF- $\alpha$ respectively.

Assesement of RA was performed using the DAS28, the values ranged between 4.10 and 6.80 with mean $5.11 \pm 0.90$ (Table 2)
TABLE (1) Statistical analysis of the studied cases according to clinical parameters $(\mathrm{n}=20)$

\begin{tabular}{|c|c|c|c|c|}
\hline & PD & CAL & PI & GI \\
\hline Min. - Max. & $3.0-6.0$ & $1.0-7.0$ & $1.0-2.75$ & $1.50-2.50$ \\
\hline Mean \pm SD. & $4.75 \pm 0.85$ & $3.75 \pm 1.62$ & $1.84 \pm 0.50$ & $1.88 \pm 0.38$ \\
\hline Median & 5.0 & 4.0 & 1.88 & 1.88 \\
\hline
\end{tabular}

TABLE (2) Statistical analysis of the studied cases according to lab investigation $(n=20)$

\begin{tabular}{|c|c|c|c|}
\hline & Min. - Max. & Mean \pm SD. & Median \\
\hline GCF-Il-6 & $1.60-33.20$ & $13.50 \pm 11.28$ & 11.0 \\
\hline GCF-TNF- $\alpha$ & $1.20-12.0$ & $4.34 \pm 2.61$ & 3.70 \\
\hline DSA28 & $4.10-6.80$ & $5.11 \pm 0.90$ & 5.04 \\
\hline
\end{tabular}

A positive correlation was found between DAS28 and both IL- 6 and TNF- $\alpha(p=0.694-r=0.001)$ and $(\mathrm{p}=0.604-\mathrm{r}=0.005)$ for IL- 6 and TNF- $\alpha$ respectively and the values were statistically significant. (Table 3) (Figure 1-2)

A positive correlation was also found between DAS28 and each of PD ( $\mathrm{p}=0.246, \mathrm{r}=0.297)$, CAL $(\mathrm{p}=0.244, \mathrm{r}=0.300), \mathrm{PI}(\mathrm{p}=0.406, \mathrm{r}=0.076)$ and $\mathrm{GI}$ $(\mathrm{p}=0.340, \mathrm{r}=0.142)$ however the correlation was not statistically significant. (Table 3 )

TABLE (3) Relation between DSA28 with periodontal parameters

\begin{tabular}{|c|c|c|}
\hline \multirow{2}{*}{ Parameters } & \multicolumn{2}{|c|}{ DSA28 } \\
\cline { 2 - 3 } & $\mathbf{r}$ & $\mathbf{P}$ \\
\hline IL-6 & $0.694^{*}$ & 0.001 \\
\hline TNF & $0.604^{*}$ & 0.005 \\
\hline PD & 0.246 & 0.297 \\
\hline CAL & 0.244 & 0.300 \\
\hline PI & 0.406 & 0.076 \\
\hline GI & 0.340 & 0.142 \\
\hline
\end{tabular}

r: Pearson coefficient

*: Statistically significant at $p \leq 0.05$ 


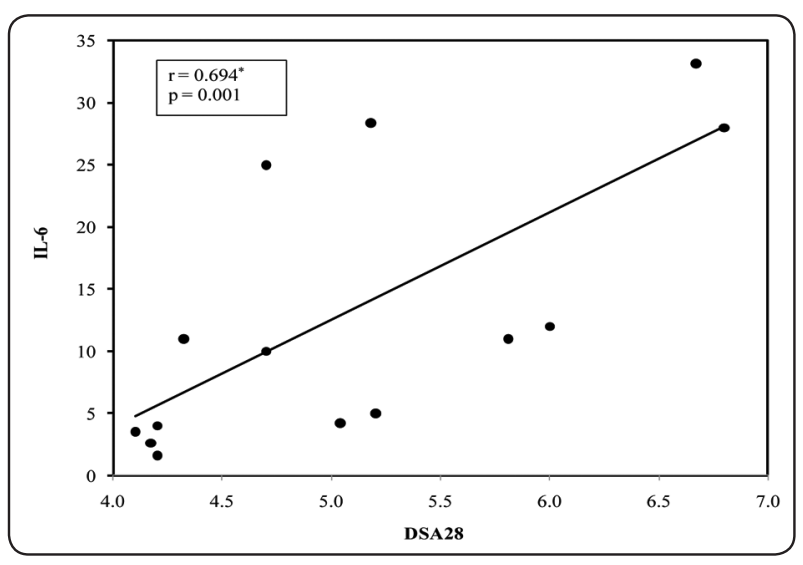

Fig. (1): Relation between DSA28 and IL-6

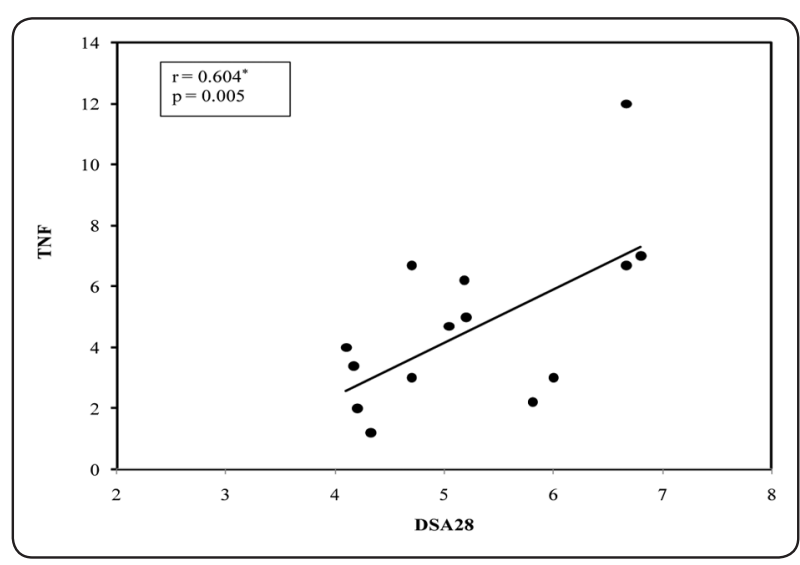

Fig. (2): Relation between DSA28 and TNF

TABLE (4): Rheumatoid disease activity compared with the severity of periodontal disease in rheumatoid arthritis subjects (CASES)

\begin{tabular}{|c|c|c|c|c|}
\hline \multirow{2}{*}{ Rhematoid disease activity } & \multicolumn{3}{|c|}{ Chronic periodontitis } & \multirow{2}{*}{ Total } \\
\cline { 2 - 4 } & mild & moderate & Severe & \\
\hline Low & $0(0 \%)$ & $0(0 \%)$ & $0(0 \%)$ & $0(0 \%)$ \\
\hline Moderate & $3(50 \%)$ & $3(100 \%)$ & $6(54.54 \%)$ & $12(60 \%)$ \\
\hline High & $3(50 \%)$ & $0(0 \%)$ & $5(45.45 \%)$ & $8(40 \%)$ \\
\hline Total & $6(100 \%)$ & $3(100 \%)$ & $11(100 \%)$ & $20(100 \%)$ \\
\hline
\end{tabular}

The rheumatoid disease activity was compared with the severity of periodontal disease (Table 4). In the RA group; 12 subjects $(60 \%)$ had moderate rheumatoid disease activity, and 8 (40\%) had severe rheumatoid disease activity. Mild periodontitis was found in 6 subjects; among whom 3 subjects (50\%) had moderate RA disease activity and 3 (50\%) had severe RA disease activity. Moderate periodontitis was found in 3 subjects, the 3 subjects had moderate rheumatoid disease activity. Severe periodontitis was found in 11 subjects, 6 (54.54\%) had moderate rheumatoid disease activity, and 5 (45.45\%) had high disease activity. This study showed that for subjects with RA, there was no significant association between rheumatoid disease activity and the severity of periodontal disease (Table 4).

\section{DISCUSSION}

Periodontal disease and rheumatoid arthritis are two of the most common chronic inflammatory diseases, Although the etiologies of these two chronic inflammatory diseases are separate, it is well recognized that pathogenic similarities exist between them. ${ }^{(23)}$

Periodontal disease is characterized by the progression of local inflammation that contributes to the clinical outcome of the disease ${ }^{(24)}$. Cytokines and chemokines lead to the migration of leukocytes to the periodontal tissues where these cells play an important role in pathogen destruction by releasing mediators in a local inflammatory response $^{(25)}$. Therefore, these and other mediators have been detected at elevated levels in the 
gingival crevicular fluid, saliva, and blood, thus being considered acceptable biomarkers for some aspects of $\mathrm{PD}^{(24,26,27)}$. Particularly, proinflammatory cytokines such as IL-1, IL-6 and TNFs have been associated with periodontal disease progression ${ }^{(28)}$ The proinflammatory cytokines (IL-1 and IL-6, TNFs have been implicated in the stimulation of osteoclastic resorption in periodontitis. ${ }^{(29)}$

In the present study the levels of Il- 6 and TNF- $\alpha$ were assessed in the gingival crevicular fluid of sites exhibiting increased probing depth and CAL. The values were $(13.50 \pm 11.28$ and $4.34 \pm 2.61)$ for the IL- 6 and TNF- $\alpha$ respectively. The DAS28 of RA correlated positively with Il-6 ( $\mathrm{r}=0.694$, $\mathrm{p}=0.001)$ and TNF- $\alpha(\mathrm{r}=0.604 \cdot \mathrm{p}=0.005)$. this is in accordance with other studies reporting that local inflammation caused by periodontitis may induce systemic inflammatory response. ${ }^{(23,30)}$ Periodontal inflammation can lead to elevated levels of cytokines such as IL-1, IL-6, and TNF, which trigger the release of CRP from the liver, thus contributing to systemic inflammation enhancing the risk of other systemic diseases including RA. . $^{31-33)}$

In this regard this could suggest that TNF- $\alpha$ and IL-6 from the gingival crevicular fluid could be used as a marker for RA activity as a non-invasive method.

In the present study however, the DAS28 for RA didn't show significant correlation with clinical parameters of periodontitis PD, CAL, PI, GI and there was no significant association between rheumatoid disease activity and the severity of periodontal disease. These data are consistent with the findings of Kasser et al. ${ }^{(34)}$, Josef et al ${ }^{(35)}$ and Khantisopon $\mathrm{N}$ et $\mathrm{al}^{(36)}$ who found no correlation between the rheumatoid disease activity and the severity of periodontal disease.

On the other hand Wolff et al. ${ }^{(37)}$ examined the association between early RA and periodontitis and reported that RA patients had a greater number of missing teeth, deeper periodontal pockets, and a higher prevalence of bleeding on probing with comparable oral hygiene between groups.

In the present study although the levels of local inflammatory cytokines in the gingival crevicular fluid were elevated with increased rheumatoid arthritis disease activity, the elevated level of cytokine didn't correlate significantly with the clinical parameters of periodontitis. This may be due to the fact that all RA subjects are treated with non steroidal anti-inflammatory drugs or immune suppressant corticosteroids, thereby possibly reducing clinical evidence of periodontal disease. Also it is well known that the subgingival biofilm is a key etiologic factor in periodontitis together with other important factors that influence progression of the periodontal disease including smoking ${ }^{(38)}$, age, stress and psychological factors ${ }^{(39)}$ and existing attachment loss ${ }^{(40)}$.

In light of the above study a possible link could exist between rheumatoid arthritis and periodontitis since active RA disease is characterized by elevated levels of circulating proinflammatory cytokines which were also detected in the gingival crevicular fluid. This would render the RA patient more susceptible to periodontal disease if other factors affecting disease progression coexist. Other studies concluded that the occurrence and severity of periodontitis was found to be higher in RA subjects $^{(35.41,42)}$

This study highlights the potential for a relationship between two of the most common and debilitating chronic inflammatory conditions affecting humans and warrants further detailed investigation. Further studies with larger sample sizes are needed to unravel the pathogenic relation between periodontitis and RA on both a clinical and biologic level. This may result in new opportunities for intervention that will modify the course of these diseases. 


\section{REFERENCES}

1. Newman MG: Classification and epidemiology of periodontal disease. In Newman MG; Takei $\mathrm{HH}$; Klokkevold PR; Carrana FA, editors: Carranza's Clinical Periodontology, 11th Edition. Philadelphia: W.B. Saunders Company, 2012. page 41.

2. Chiu B. Multiple infections in carotid atherosclerotic plaques. Am Heart J 1999;138:S534e6.

3. Madianos PN, Lieff S, Murtha AP, Boggess KA, Auten Jr RL, Beck JD. Maternal periodontitis and prematurity. Part II: maternal infection and fetal exposure. Ann Periodontol 2001;6:175e82.

4. van Winkelhoff AJ, Slots J. Actinobacillus actinomycetemcomitans and Porphyromonas gingivalis in nonoral infections. Periodontol. 2000 1999;20: 122e35.

5. Dye BA, Choudhary K, Shea S, Papapanou PN (2005) Serumantibodies to periodontal pathogens and markers of systemicinflammation. J Clin Periodontol 32(12): 1189-1199

6. Sandros J, Karlsson C, Lappin DF, Madianos PN, Kinane DF, Papapanou PN (2000) Cytokine responses of oral epithelial cells to Porphyromonas gingivalis infection. J Dent Res 79(10):1808-1814

7. Mercado FB, Marc hall R, Bartold PM: Inter-relationship between RA and periodontal disease a review. J clin periodontal 2003, 30:761-772.

8. Helminen-Pakkala E. The periodontal condition of subjects with rheumatoid arthritis. Med Hyg (Geneva). 1972;30:1456-1457.

9. Marshal RI, Klestov AC, et al. Is there a relationship between rheumatoid arthritis and periodontal disease? J Clin Periodontol. 2000;27:267-272.

10. Mercado FB, Marshall RI, Klestov AC, et al. Relationship between rheumatoid arthritis and periodontitis. J Periodontol. 2001;72:779 -787

11. Aletaha D, Neogi T, Silman AJ, Funovits J, Felson DT, Bingham CO, et al. 2010 Rheumatoid Arthritis classification creiteria: an American College of Rhematology/ European league Against Rheumatism Collaborative initiative. Ann Rheum Dis 2010;69:1558-8.

12. Armitage GC. Development of a classification system for periodontal diseases and conditions. Ann Periodontol $1999 ; 4: 1-5$
13. Aletaha D, Landewe R,Karonitch T, Barthon J, Boers M, Bombardier C, et al Reporting disease activity in clinical trials of patients with Rhematoid Arthritis: EULAR/ ACR collaborative recommendations. Arthritis Rheum 2008;59:137-7

14. van der Heijde DMI, vant Hof MA, van Riel PL, Theunisse LA, Lubberts EW, van Leeuween MA, et al. Judging dsease activity in clinical practice in rheumatoid arthritis: first step in the development of a disease activity score. Ann Rheum Dis 1990;49:916-20.

15. Prevoo ML, van't Hof MA, Kuper HH, van Leeuwen MA, van de Putte LB, van Riel PL. Modified disease activity scores that include twenty-eight joint counts. Development and validation in a prospective longitudinal study of patients with rheumatoid arthritis. Arthritis Rheum 1995;38:44-8

16. Glavind L, Loe H. Error in the clinical assessment of periodontal sestruction. J Periodont Res. 1967;2:180

17. Silness J, Loe H. Periodontal disease in pregnancyII: Correlation between oral hygiene and periodontal condition. Acth Odont. Scan 1964;22:121.

18. Lobene RR, Weatherford T, Ross NM. Modified gingival index. Clin Prev Dent 1986;8:3-6.

19. Goutoudi P, Diza E, Arvanitidou M. Effect of periodontal therapy on crevicular fluid interleukin-6 and interleukin-8 levels in chronic periodontitis. Int J Dent 2012;12:29-36.

20. TNF- $\alpha$ 021, Lab systems Diagnostics Oy, Orgenium Laboratories Business Unit, Tiilitie 3, Fin- 07120 Vantaa FINLAND

21. Nakasima K, Giannopoulou C, Andersen E, Roehrich NBrochut P, Dubrez B, Cimasoni G. A longitudinal study of various crevicular fluid components as markers of periodontal disease activity. J Clin Periodontol. 1996; 23: 832-838.

22. Eley B. M., Cox S. W.: Cathepsin B/1-, elastase-, tryptase, trypsin-, dipeptidyl peptidase IV-like activities in GCF: correlation with clinical parameters in untreated chronic periodontitis patients. J. Periodont. Res. 1992;27:62-69.

23. Bartold PM, Marshall RI, Haynes DR. Periodontitis and rheumatoid arthritis: a review. J Periodontol. 2005;76(Suppl 11):2066Y2074.

24. Sexton W. M., Lin Y., Kryscio R. J., Dawson D. R., III, Ebersole J. L., Miller C. S. Salivary biomarkers of periodontal disease in response to treatment. Journal of Clinical Periodontology. 2011;38(5):434-441. 
25. Graves D. T. The potential role of chemokines and inflammatory cytokines in periodontal disease progression. Clinical Infectious Diseases. 1999;28(3):482-490.

26. Silva M. J. B., Sousa L. M. A., Lara V. P. L., et al. The role of iNOS and PHOX in periapical bone resorption. Journal of Dental Research. 2011;90(4):495-500.

27. Kejriwal S., Bhandary R., Thomas B., Kumari S. Estimation of levels of salivary mucin, amylase and total protein in gingivitis and chronic periodontitis patients. Journal of Clinical and Diagnostic Research. 2014;8(10)

28. Correa F. O. B., Gonçalves D., Figueredo C. M. S., Bastos A. S., Gustafsson A., Orrico S. R. P. Effect of periodontal treatment on metabolic control, systemic inflammation and cytokines in patients with type 2 diabetes. Journal of Clinical Periodontology. 2010;37(1):53-58.

29. Stashenko P., Wang C. Y., Tani-Ishii N., Yu S.M. Pathogenesis of induced rat periapical lesions. Oral Surgery, Oral Medicine, Oral Pathology. 1994;78(4): 494-502.

30. Jain A, Batista EL Jr, Serhan C, et al. Role for periodontitis in the progression of lipid deposition in an animal model. Infect Immun. 2003;71:6012Y6018.

31. Seymour GJ, Taylor JJ. Shouts and whispers: an introduction to immunoregulation in periodontal disease. Periodontol 2000. 2004;35:9Y13.

32. Cullinan MP, Ford PJ, Seymour GJ. Periodontal disease and systemic health: current status. Aust Dent J. 2009;54:S62YS69.

33. Pizzo G, Guiglia R, Lo Russo L, et al. Dentistry and internal medicine: from the focal infection theory to the periodontal medicine concept. Eur J Intern Med. 2010;21:496Y502.

34. Kasser UR, Gleissner C, Dehne F, MichelA, WillershausenZonnchen B, Bolten WW (1997) Risk for periodontal disease in patients with longstanding rheumatoid arthritis. Arthritis Rheum 40(12):2248-2251

35. Joseph R, Rajappan S, Nath SG, Paul BJ. Association between chronic periodontitis and rheumatoid arthritis: a hospital-based case-control study. Rheumatol Int. 2013 Jan;33(1):103-9.

36. Khantisopon N, Louthrenoo W, Kasitanon N, Sivasomboon C, Wangkaew S, Sang-In S, Jotikasthira N, Bandhaya P. Periodontal disease in Thai patients with rheumatoid arthritis Int J Rheum Dis. 2014 Jun;17(5):511-8.

37. Wolff B, Berger T, Frese C, Max R, Blank N, Lorenz HM, et al. Oral status in patients with early rheumatoid arthritis: a prospective, case-control study. Rheumatology (Oxford) 2014;53:526-31

38. Albandar JM, Streckfus CF, Adesanya MR, Winn DM. Cigar, pipe, and cigarette smoking as risk factors for periodontal disease and tooth loss. J Periodontol 2000;71:1874e81.

39. Peruzzo DC, Benatti BB, Ambrosano GM, NogueiraFilho GR, Sallum EA Casati MZ. A systematic review of stress and psychological factors as possible risk factors for periodontal disease. J Periodontol 007;78:1491e504.

40. Haffajee AD, Socransky SS, Lindhe J, Kent RL, Okamoto H, Yoneyama T. Clinical risk indicators for periodontal attachment loss. J Clin Periodontol 1991;18: 117e25.

41. Mercado F, Marshall RI, Klestov AC, Bartold PM: Is there a relationship between rheumatoid arthritis and periodontal disease? J Clin Periodontol 2000; 27: 267-272.

42. de Smit MD, Westra J, Vissink A. Doornbos-van der Meer B, Brouwer E, van Winkelhoff AJ. Periodontitis in established rheumatoid arthritis patients: a cross-sectional clinical, microbiological and serological study. Arthritis Res Ther. 2012;14:R222. 